\title{
Drug-eluting stent for acute Blalock-Taussig shunt thrombosis in a child-case report
}

\author{
Arun Gopalakrishnan ${ }^{1 *} \mathbb{D}$, Bijulal Sasidharan ${ }^{1}$, Sabarinath Menon² and Kavassery Mahadevan Krishnamoorthy ${ }^{1}$
}

\begin{abstract}
Background: Blalock-Taussig shunt (BTS) continues to have a relatively high operative and short-term mortality, even in the current era. We report the use of drug-eluting stent in a child with acute shunt thrombosis, which has not been reported in the literature to date.

Case presentation: A 7-month-old boy with double outlet right ventricle, severe pulmonary stenosis, and normally related great arteries underwent BTS placement for cyanotic spells. Ten days after discharge, he presented with shock due to a blocked BTS. He underwent emergency percutaneous revascularization of the shunt with a drugeluting stent and is doing well at 9 months' follow-up on dual antiplatelet therapy.
\end{abstract}

Conclusions: Drug-eluting stents may be used in children with BTS thrombosis.

Keywords: Blalock-Taussig shunt, Cyanosis, Aortopulmonary shunt, Cyanotic spell, Double outlet right ventricle

\section{Background}

The outcomes of congenital heart diseases have considerably improved over the past two decades following improvements in surgical techniques, interventions, and intensive care. However, Blalock-Taussig shunt continues to have relatively higher operative and shortterm mortality, even in the current era [1]. Systemic to pulmonary artery shunt occlusion constitutes an emergency where timely intervention can be lifesaving. We report the use of drug-eluting stent in a child with acute shunt thrombosis, which has not been reported in literature till date.

\section{Case presentation}

A 7-month-old boy weighing $6 \mathrm{~kg}$ was admitted to the intensive care with cyanotic spell. He was diagnosed to have double outlet right ventricle with severe pulmonary stenosis and normally related great arteries. He was stabilized with intravenous morphine, ketamine, and esmolol infusion. The branch pulmonary arteries were

\footnotetext{
* Correspondence: arungopalakrishnan99@gmail.com

${ }^{1}$ Department of Cardiology, Sree Chitra Tirunal Institute for Medical Sciences and Technology, Thiruvananthapuram, Kerala 695011, India

Full list of author information is available at the end of the article
}

noted to be hypoplastic, and a large conal branch was noted across the right ventricular outflow tract, precluding an emergent biventricular repair. Hence, a 4-mm polytetrafluoroethylene Blalock-Taussig shunt was placed between the right brachiocephalic trunk and the main pulmonary artery. The oxygen saturation improved to $80 \%$, and he was discharged on day 16 on aspirin 5 $\mathrm{mg} / \mathrm{kg} /$ day and clopidogrel $0.5 \mathrm{mg} / \mathrm{kg} /$ day.

He was readmitted in a collapsed state 10 days later. Shunt murmur was absent, and echocardiography suggested blocked Blalock-Taussig shunt. After intubation and mechanical ventilation, he was rushed to the catheterization lab where angiography confirmed totally occluded Blalock-Taussig shunt. One hundred units/ kilogram of intravenous heparin bolus was administered. Over a 5F Judkin's right guide catheter from the femoral arterial access, the aortopulmonary shunt was wired with a hydrophilic coated coronary guidewire into the left pulmonary artery. The blocked shunt was predilated with a $4 \mathrm{~mm} \times 8 \mathrm{~mm}$ non-compliant balloon at $10 \mathrm{~atm}$ following which a $4 \mathrm{~mm} \times 18 \mathrm{~mm}$ sirolimus-eluting stent was deployed at nominal pressures covering both ends of the shunt (Fig. 1). The saturation improved to $85 \%$, and he was discharged on dual antiplatelets. Aspirin was 


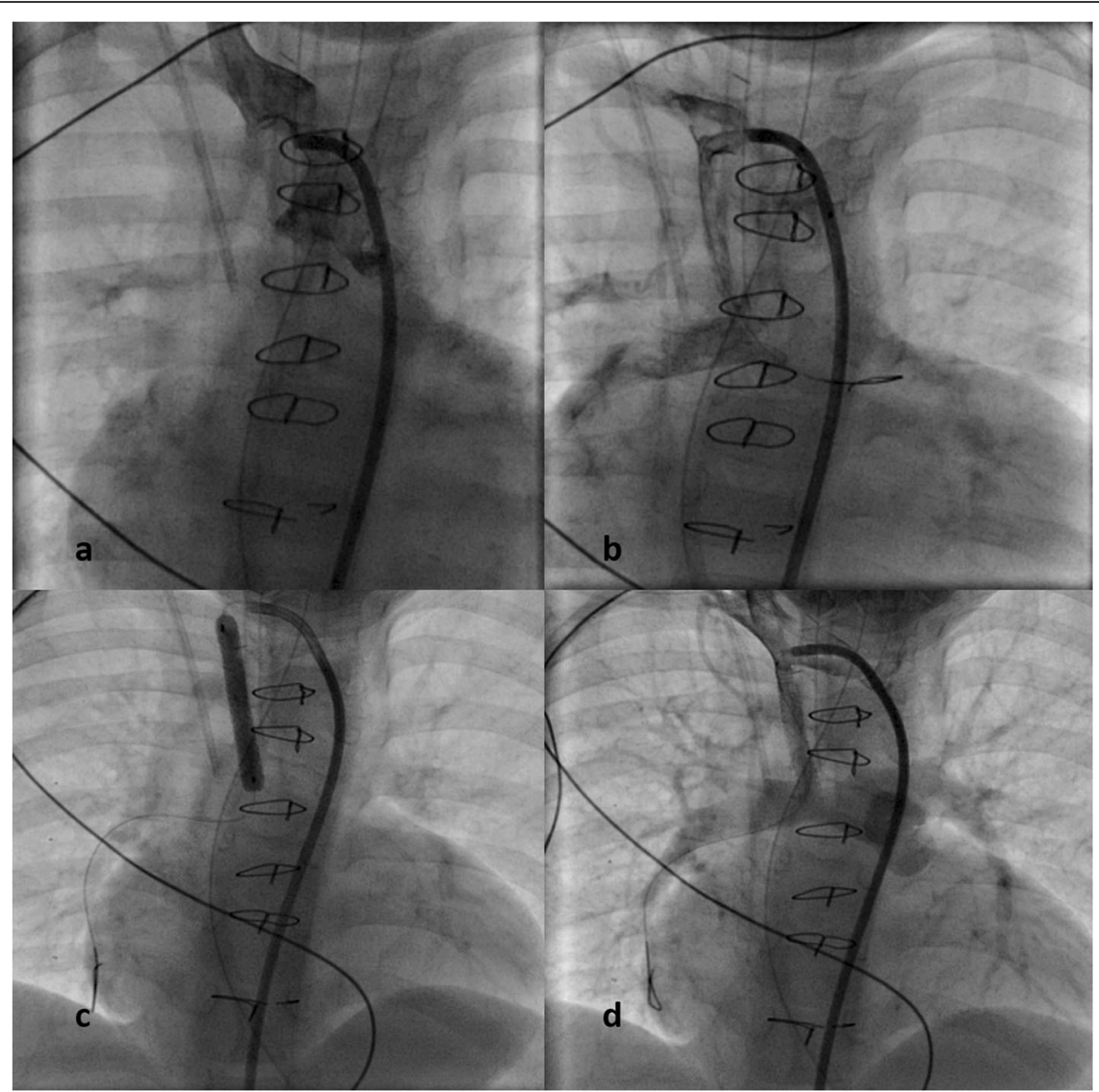

Fig. 1 Serial fluoroscopy stills in the posteroanterior projection with $20^{\circ}$ cranial angulation. In a, right subclavian artery angiography fails to opacify the Blalock-Taussig shunt, but is opacified in the angiogram after wiring and balloon dilatation (b). After parking the coronary wire in the distal right pulmonary artery, stent was deployed (c) restoring the entire lumen of the shunt opacifying both pulmonary arteries (d)

continued at $5 \mathrm{mg} / \mathrm{kg} /$ day, and clopidogrel dose was increased to $1 \mathrm{mg} / \mathrm{kg} /$ day. The stent remained patent at 9 months' follow-up. He is planned for reassessment of intracardiac repair on follow-up.

\section{Discussion}

While stenting of the Blalock-Taussig shunt is a viable option to salvage acute occlusion of the Blalock-Taussig shunt, the use of drug-eluting stents is not previously described particularly in children. Bare metal stents were not readily available in our country at the time of the procedure which limited their use. Low weight at surgery, poor pulmonary artery anatomy, vascular distortion, smaller shunt size, and dehydration are some of the precipitants of acute shunt occlusion [2, 3]. Neonatal Blalock-Taussig shunts are associated with higher morbidity and mortality than those done in older children [4]. Reports suggest that the application of sirolimuseluting stents in young children is associated with higher peak blood levels and delayed clearance of sirolimus from the body, but with no clinically observable adverse effects [5]. Preliminary reports from our ongoing study and other published data [6] suggest that while sirolimus levels are high on day 1 , it is rapidly cleared off from the body in neonates and young children following implantation of drug-eluting stents. The relatively high drug levels in the initial days after stenting may potentially be beneficial for rehabilitation of occluded Blalock-Taussig shunts which are known to have high rates of thrombosis and reocclusion. Relatively rapid drug clearance seems to circumvent the delayed immunosuppressive complications. The use of dual antiplatelet therapy may also be beneficial in this setting to protect the shunt, which serves as the lifeline of the child [7].

\section{Conclusions}

This case demonstrates that drug-eluting stents may be used in children with Blalock-Taussig shunt thrombosis. While a single case report does not imply generalizability, further studies would be useful to evaluate the use of drug-eluting stents in children. 


\section{Acknowledgements}

Not applicable

\section{Authors' contributions}

AG and KMK prepared the manuscript. Data was collected by AG and BL. BL, $S M$, and KMK revised the manuscript. All read and approved the final manuscript.

\section{Authors' information}

The authors are part of the Pediatric Cardiac Team of Sree Chitra Tirunal Institute for Medical Sciences and Technology, which is an Institute of National Importance under the Government of India and is among the largest pediatric cardiac centers in the country.

\section{Funding}

This research received no specific grant from any funding agency,

commercial or not-for-profit sectors.

\section{Availability of data and materials}

All data relevant are included in this published article [and its supplementary information files].

\section{Ethics approval and consent to participate}

All procedures followed were in accordance with the ethical standards of the responsible committee on human experimentation (institutional and national) and with the Helsinki Declaration of 1964 and later revisions. Informed written consent was obtained from the parents of the patient for being included in the case report. No patient identity particulars have been disclosed.

\section{Consent for publication}

Informed consent was obtained from the parents of the patient for using the data without patient particulars for publication.

\section{Competing interests}

The authors declare that they have no competing interests.

\section{Author details}

'Department of Cardiology, Sree Chitra Tirunal Institute for Medical Sciences and Technology, Thiruvananthapuram, Kerala 695011, India. ${ }^{2}$ Department of Cardiovascular and Thoracic Surgery, Sree Chitra Tirunal Institute for Medical Sciences and Technology, Thiruvananthapuram, Kerala 695011, India.

Received: 20 May 2020 Accepted: 7 August 2020

Published online: 26 August 2020

\section{References}

1. Dirks V, Prêtre R, Knirsch W et al (2013) Modified Blalock Taussig shunt: a not-so-simple palliative procedure. Eur J Cardiothorac Surg. 44(6):1096-1102. https://doi.org/10.1093/ejcts/ezt172

2. Dorobantu DM, Pandey R, Sharabiani MT et al (2016) Indications and results of systemic to pulmonary shunts: results from a national database. Eur J Cardiothorac Surg. 49(6):1553-1563. https://doi.org/10.1093/ejcts/ezv435

3. Sivakumar K, Shivaprakasha K, Rao SG, Kumar RK (2001) Operative outcome and intermediate term follow-up of neonatal Blalock-Taussig shunts. Indian Heart J 53(1):66-70

4. Singh SP, Chauhan S, Choudhury M et al (2014) Modified Blalock Taussig shunt: comparison between neonates, infants and older children. Annals of Cardiac Anaesthesia. 17(3):191. https://doi.org/10.4103/0971-9784.135847

5. Lee K-J, Seto W, Benson L, Chaturvedi RR (2015) Pharmacokinetics of sirolimus-eluting stents implanted in the neonatal arterial duct. Circ Cardiovasc Interv 8(5). https://doi.org/10.1161/CIRCINTERVENTIONS.114 002233

6. Sivakumar K, Pavithran S, Sonawane B, Rajendran M, Ramasamy R (2020) Serum sirolimus levels after implantation of third generation drug eluting cobalt chromium coronary stent in ductus arteriosus in neonates with ductdependent pulmonary circulation. Pediatr Cardiol. Published online May 30. https://doi.org/10.1007/s00246-020-02381-4

7. Gillespie MJ, Rome JJ (2008) Transcatheter treatment for systemic-topulmonary artery shunt obstruction in infants and children. Catheterization Cardiovasc Interventions. 71(7):928-935. https://doi.org/10.1002/ccd.21448

\section{Publisher's Note}

Springer Nature remains neutral with regard to jurisdictional claims in published maps and institutional affiliations.

\section{Submit your manuscript to a SpringerOpen ${ }^{\circ}$ journal and benefit from:}

- Convenient online submission

- Rigorous peer review

- Open access: articles freely available online

High visibility within the field

- Retaining the copyright to your article

Submit your next manuscript at $\boldsymbol{\nabla}$ springeropen.com 